\title{
Cuidado e desenvolvimento em crianças escolares de Salvador
}

\author{
Care and development in schoolchildren \\ in Salvador, Bahia, Brazil
}

Vania BUSTAMANTE

\begin{abstract}
Resumo
Analisou-se a relação entre família, escola, serviços de saúde e comunidade, enfocando o cuidado e o desenvolvimento infantil em um bairro de baixa renda de Salvador, Bahia. Entende-se cuidado como atenção de qualidade oferecida por adultos e como construção de projetos de pessoa em práticas cotidianas marcadas por relações de poder. Realizou-se observação participante e entrevistas com moradores do bairro e com profissionais de saúde e educação, a partir das quais foi selecionado um caso típico. Identificou-se, por um lado, diferenças na maneira com que os profissionais falam sobre crianças com desempenho escolar insatisfatório e, por outro lado, a família e os espaços de parentesco, nos quais opera uma forma diferente de pensar a educação e onde as crianças encontram um olhar ampliado sobre suas possibilidades. Destaca-se a importância de que os estudos contemplem os diferentes contextos que integram o cotidiano infantil e que a perspectiva da família e parentes seja valorizada.
\end{abstract}

Unitermos: Cuidado da criança; Desenvolvimento infantil; Escola; Família.

\begin{abstract}
The relationship between family, school and health services was analyzed considering the development and care of children living in a low income neighborhood. We understand care as quality attention provided by adults and also as the day-to-day practical construction of personal projects, a process marked by power relations. We conducted participant observation and interviews with residents in the neighborhood studied and with health professionals and education workers. From among these a representative case was selected. The analysis identified differences in the way professionals talk about children with low school performance. By contrast in family and kinship spaces a different way of thinking about education operates, in that children encounter an expanded view of themselves and of their potential. We stress as a vital necessity that studies include all the different day-to-day contexts that comprise children's experiences and emphasize that professionals and workers take into consideration and attribute value to the perspective of the family and relatives.
\end{abstract}

Uniterms: Child Care; Child development; School; Family.

Tendo por interesse refletir sobre as peculiaridades do desenvolvimento de crianças escolares que moram em bairros urbanos de baixa renda, considerou-se necessário incluir a discussão sobre o conceito de

\section{$\boldsymbol{\nabla} \mathbf{v} \boldsymbol{v}$}

1 Universidade Federal da Bahia, Instituto de Psicologia. R. Aristides Novis, 2, Estrada de São Lázaro, 40210-730, Salvador, BA, Brasil. E-mail: $<$ vaniabus@yahoo.com>.

Apoio: Conselho Nacional de Desenvolvimento Científico e Tecnológico e Fundação de Amparo à Pesquisa do Estado da Bahia, que concederam bolsas de doutorado e pós-doutorado, respectivamente.

Agradecimentos: À Cecilia McCallum. 
contexto de desenvolvimento para abordar este tema. Lordelo (2002) destaca que o contexto tem múltiplos e complexos significados em Psicologia e que não se refere apenas a um espaço físico. Apontando que "o estudo das relações entre contexto e desenvolvimento deve incluir facetas dos sistemas sociais, dos ambientes físicos e das pessoas como participantes ativos, interagindo e influenciando-se mutuamente no tempo" (Lordelo, 2002, p.9). Para a referida autora, essa forma de compreender o contexto expressa o amadurecimento da Psicologia do Desenvolvimento, que passa a reconhecer a possibilidade de caminhos diversos e a utilizar modelos de análise não determinísticos, nos quais é cada vez mais importante estudar a diversidade, buscando fortalecer teorias específicas e pensar modelos de intervenção.

Nesse sentido, quando se trata de grupos urbanos de baixa renda, surgem algumas perguntas sobre as implicações para o desenvolvimento, em longo prazo, de modos de vida que parecem precários ou deficientes, questionando em que medida os ambientes abrem possibilidades ou impõem limitações.

Os estudos envolvendo crianças que moram em bairros populares frequentemente focam nos temas família e escola. Alguns autores chamam a atenção sobre a alta proporção de crianças com desempenho escolar insatisfatório nos grupos populares e apontam a necessidade de pensar sobre essa situação a partir da relação entre família e escola (Oliveira, Bisinoto \& Marinho-Araújo, 2010). Chechia e Andrade (2005) problematizam a relação entre família e escola ao mostrar que existem diferentes formas de compreender o significado da escola e que o fracasso escolar não exclui a preocupação dos pais com os filhos. Por outro lado, estudos sobre a relação entre família e serviços de saúde, no que diz respeito ao cuidado de crianças, mostram que existem diferentes racionalidades (Bustamante \& McCallum, 2010), em parte associadas a diferenças de classe social (Oliveira \& Bastos, 2000). As pesquisas apontam a grande preocupação das famílias no cuidado de crianças, ainda que, frequentemente, os familiares não sigam as recomendações dos profissionais de saúde (Bustamante \& Trad, 2007; Loyola, 1984).

Bastos (2000) formulou a categoria "modos de 508 partilhar" para compreender as relações de crianças em seu cotidiano familiar. A autora analisa as diferentes formas de participação ativa das crianças no cotidiano familiar, que funciona como um espaço que fortalece o desenvolvimento infantil. A realização de tarefas domésticas é estimulada pelos adultos, que as consideram importantes para que a criança desenvolva habilidades necessárias ao contexto em que vive. Bastos (2000) chama a atenção sobre a importância de "estudar contextos de desenvolvimento disponíveis para a criança brasileira e compreender essa realidade a partir dela própria, mais do que pelo confronto com parâmetros externos... de avaliação e comparação" (p.30).

O presente artigo pretende ampliar esse debate ao analisar como se dá a relação entre família, escola, comunidade e serviços de saúde, examinando qual a participação da criança no próprio desenvolvimento. Propõe-se construir essa reflexão com base no conceito de cuidado. Carvalho e Lordelo (2002) apontam que a intensidade e qualidade da atenção do adulto é uma das dimensões mais relevantes para caracterizar o ambiente de desenvolvimento da criança e, frequentemente, é identificada como sinônimo de cuidado. As autoras destacam que "as repercussões do tipo de cuidado adulto, na forma de estilos de interação e relação entre adulto e criança, parecem ter consequências marcantes em diversas dimensões do desenvolvimento, nas áreas cognitiva, social e emocional" (p.238). Nesse sentido, a deficiência de atenção adulta é considerada um risco potencial para o desenvolvimento como resultado socialmente desejado.

Defini-se cuidado infantil como construção de projetos de pessoa em práticas cotidianas que se dão em um marco de relações de poder. O conceito de cuidado aqui proposto baseia-se na noção utilizada por Ayres (2001, 2004a, 2004b), como construção de projetos de felicidade, incorporando, assim, uma perspectiva etnográfica e sociocultural, partindo, portanto, de conceitos nativos e considerando as diferenças de classe, raça/cor/etnia, geração e as diferenças de sexo (Carvalho, 1999; Schraiber, 2005). Defende-se que cuidado envolve a construção de projetos no sentido destacado por Rabelo (1999): "práticas forjadas em contextos de ação/atenção perante as coisas" (p.224) relacionadas com a criança como pessoa. Assim como Pina Cabral (2007), defende-se que a construção da pessoa é permanente e envolve processos simbólicos e materiais que integram individualismo e holismo. 
A discussão defendida sobre o cuidado dialoga com as considerações de Carvalho e Lordelo (2002) ao considerar a qualidade da atenção do adulto como sinônimo de cuidado. Por outro lado, aqui argumenta-se que as diferenças entre os adultos cuidadores estão associadas com a construção de projetos de pessoa distintos que, por sua vez, estão ligados não apenas a diferenças entre os agentes, mas a múltiplas posições sociais (Bourdieu, 1996) e a desigualdades no capital global.

Teve-se como objetivo de pesquisa compreender como se dá o desenvolvimento de crianças em idade escolar em um bairro de baixa renda de Salvador (BA), considerando a participação de cuidadores de diferentes áreas. Além disso, pretende-se contribuir para a reflexão conceitual sobre contextos de desenvolvimento ao analisar as possibilidades teóricas da categoria cuidado, buscando compreender, simultaneamente, a participação de diferentes agentes no desenvolvimento infantil.

Concorda-se com as preocupações expressas por outros autores quanto à necessidade de a pesquisa acadêmica se afinar mais com a realidade brasileira. Silva (2003) afirma que "o desenvolvimento de uma psicologia ética no Brasil supõe o enfrentamento dos desafios de uma agenda própria" (p. 95), sendo preciso identificar questões cruciais e transformá-las em objeto de investigação, buscando-se produzir um conhecimento esclarecedor de nossa realidade social. Para trabalhar nessa direção, o referido autor chama a atenção sobre a necessidade de repensar o conceito de pessoa presente na Psicologia e nas Ciências Sociais.

As escolhas metodológicas adotadas para atender aos objetivos deste estudo são discutidas a seguir.

\section{Método}

A análise desenvolvida aqui se deu com base em três anos de trabalho de campo, entre 2003 e 2006, com moradores de um bairro de baixa renda de Salvador (BA).

\section{Participantes}

Todos os participantes ${ }^{2}$ da pesquisa tinham em comum o fato de passarem grande parte do tempo em Prainha - bairro localizado no subúrbio ferroviário de Salvador-, onde alguns moravam e outros trabalhavam. Trata-se de um bairro que possui características comuns a outros bairros populares: serviços insuficientes, infraestrutura urbana precária, algumas ruas sem asfalto, carência de espaços verdes e de lazer, presença de casas "em construção", entre outras. Os moradores têm baixo nível de escolaridade e de renda. Alternam períodos de emprego e desemprego. Entre os homens, os empregos mais comuns são de segurança e serviços gerais; entre as mulheres, vendas e serviço doméstico. Os relatos sobre episódios de violência são frequentes, incluindo violência doméstica, brigas entre vizinhos e violência perpetuada pela polícia. Ao mesmo tempo, observa-se a presença crescente de instituições - Unidade de Saúde da Família, escolas, creches, posto de polícia -, e de programas sociais.

A Unidade de Saúde da Família funciona em um local que foi construído em 2002 como parte de um acordo entre uma "ONG internacional" e uma das associações de moradores do bairro. Desde o início se estabeleceram três equipes, cuja conformação segue as regras estabelecidas para o Programa de Saúde da Família (PSF): cada equipe deve ter três profissionais de cursos superiores (Medicina, Enfermagem e Odontologia), três de nível médio (dois auxiliares de enfermagem e um auxiliar de dentista) e cinco ou seis agentes comunitários de saúde. Além dos profissionais de cada equipe, existe pessoal administrativo, recepcionistas, pessoal de limpeza e de segurança.

A escola São Lucas faz parte da rede municipal e oferece educação infantil e ensino até a quarta série. A educação infantil, para crianças a partir de quatro anos, foi implantada em 2005, sendo oferecida em dois níveis, chamados "Pré Um" e "Pré Dois". Na escola trabalham 13 professoras e apenas um professor - a maioria foi contratada mediante concurso público e tem formação universitária -, uma estagiária estudante de Pedagogia, uma bibliotecária, alguns auxiliares

$\boldsymbol{\nabla} \mathbf{v} \mathbf{v}$

2 Este e todos outros nomes usados no texto são fictícios. 
administrativos e de serviços gerais. A maior parte dos professores e funcionários trabalha nos dois turnos.

Devido às limitações de espaço deste artigo, optou-se por apresentar um único caso que foi considerado típico do cotidiano de Prainha, de modo que partiu-se da descrição e análise do cotidiano de Bruna, uma menina que, na época da coleta de dados, tinha 6 anos. Bruna e sua família participaram da pesquisa desde o início. Foi possível visitar continuamente a casa de Bruna e a família dela, assim como sua escola, a Unidade de Saúde da Família que a atendia e a Igreja Pentecostal que ela e sua família frequentavam.

Bruna morava com a mãe, Carla, e com as três irmãs mais velhas, filhas de duas uniões anteriores de Carla. Também foi possível conhecer Tinho, o pai de Bruna, que morava junto com Carla e as quatro meninas em um cômodo localizado ao lado da casa dos irmãos de Carla. Assim, além dos pais e das irmãs, Bruna tinha contato constante com os tios e primos maternos. 0 contato com a família paterna, que morava em ruas próximas, era menos constante. Também faziam parte do cotidiano de Bruna vários adultos e crianças que frequentavam a Igreja Filho de Deus, uma organização Pentecostal localizada em frente à sua casa e que era frequentada por vários membros da família. As condições de vida eram bastante precárias, dado que a única renda fixa provinha do programa Bolsa Família. De forma complementar, Tinho realizava trabalhos eventuais e, às vezes, dividia a renda entre a família atual e os cinco filhos de duas uniões anteriores.

\section{Instrumentos e Procedimentos}

A observação participante se deu nos seguintes períodos: três anos com os membros de sete famílias, seis meses em uma unidade de saúde da família e três meses em uma escola pública. O trabalho de investigação combinou visitas e participações em atividades cotidianas tais como: assistir tevê, cozinhar ou lavar roupas com moradores do bairro; atendimentos, visitas domiciliares e reuniões de equipe com profissionais de saúde; aulas, recreio e reuniões com professores; também houve participação em alguns cultos na Igreja frequentada por Bruna e sua família.

Para Toren (1997), a observação participante é o método mais característico da abordagem etno-

510 gráfica e envolve ser, ao mesmo tempo, um participante e um observador que questiona sua própria participação e a dos outros em eventos ordinários, de maneira que nada do que é dito é considerado irrelevante. Segundo a autora, a análise etnográfica não pretende basear-se em amostras representativas, tendo por desafio, em contrapartida, conhecer o máximo possível sobre as pessoas cujas ideias e comportamentos são objeto de análise. Para tanto, é importante fazer entrevistas em profundidade com alguns informantes.

Foram realizadas entrevistas gravadas com membros de todos os grupos mencionados visando a aprofundar conteúdos identificados na observação participante. Por exemplo, perguntou-se aos adultos sobre suas expectativas em relação a ter filhos, como foi no início, o que eles consideram mais importante para criá-los e sobre a relação com parentes e com instituições. As entrevistas foram gravadas e transcritas, e o conteúdo da observação participante foi registrado em diário de campo.

Assim como na perspectiva de Jackson (1996) a etnografia é tida neste artigo como um trabalho realista motivado pelo interesse de registrar experiências humanas significativas. Desse modo, a etnografia é muito mais do que um tipo de escrita, sendo a melhor forma de entender e mostrar como vivem e como se relacionam pessoas de diferentes grupos.

A análise aconteceu em todos os momentos da pesquisa e caminhou junto com o processo de escrita (Becker, 1994). As entrevistas e as notas de campo foram transcritas, lidas e organizadas em pastas seguindo a sequência temporal. As primeiras leituras do material foram gerais. Um segundo tipo de leitura se seguiu, envolvendo a identificação de temas importantes, a seleção de trechos relacionados e a criação de novos arquivos. Novas leituras do material selecionado - e, às vezes, retorno ao material original -, foram acontecendo conforme eram construídos os argumentos do estudo. Olhares mais aprofundados sobre o mesmo material surgiram a partir desse processo. Alguns achados importantes se deram após novas leituras das mesmas notas.

Vários aspectos de diferentes propostas de análise podem ser identificados na descrição feita neste artigo. Existem elementos de análise de conteúdo, na medida em que a identificação de palavras que se 
repetiam foi um indicador de algo que podia ser importante. Também é possível estabelecer relações com a análise de discurso, considerando se prestou atenção não só às palavras, mas aos contextos relacionais - e às disputas de poder em que estes eram construídos. Por outro lado, há importantes pontos em comum com o que Minayo (2007) destaca sobre os pressupostos da análise hermenêutico-dialética. Segundo a autora, ambas as disciplinas ressaltam a importância da historicidade para entender as manifestações humanas e destacam a inexistência do observador imparcial.

Os resultados estão organizados em duas subseções: inicialmente se descreve a perspectiva que os profissionais de educação e saúde expressam sobre crianças que não atendem às demandas escolares; na segunda parte, mostra-se as possibilidades oferecidas por espaços e pessoas que se relacionam cotidianamente com as crianças no âmbito do parentesco. Na discussão e considerações finais reflete-se teoricamente sobre as diferenças que marcam as relações entre as famílias e os profissionais de saúde e educação e sobre as implicações para as práticas de cuidado infantil.

O projeto de pesquisa que deu origem a este artigo foi aprovado pelo Comitê de Ética em Pesquisa do Instituto de Saúde Coletiva da Universidade Federal da Bahia (UFBA) (Registro 035-06/CEP-ISC).

\section{Resultados}

\section{Crianças com distúrbios}

Durante a observação participante no cotidiano escolar, Janice - a professora de Bruna no Ciclo Educacional Básico (CEB) da Escola São Lucas -, e outros colegas falaram sobre as dificuldades cotidianas. Vivenciou-se algumas delas. As aulas formalmente começavam à uma hora da tarde e terminavam às cinco; no entanto, raramente isso acontecia. Por vários motivos as aulas terminavam mais cedo: falta de merenda escolar, falta de alguns funcionários, chuva ou alguma festa. Também havia ocasiões em que eram suspensas por paralisação de professores (ou funcionários) ou ausência de professores por motivos diversos. Teve-se a impressão de que era difícil permanecer quatro horas em sala de aula com os alunos.

Janice e outros professores diziam que as crianças do CEB1 estão em uma idade ideal. São crianças com quem é fácil lidar e a quem é prazeroso ensinar, pois estão na idade da alfabetização. Apesar de ter esta opinião, Janice expressou várias vezes sua frustração diante dos precários resultados com a maior parte dos alunos, inclusive Bruna. Durante a aula, quando era o momento do trabalho acadêmico, Bruna tinha dificuldade para acompanhar o que estava sendo proposto; precisava da ajuda de Janice para achar a página do livro e não conseguia realizar o que a atividade demandava: reproduzir letras, fazer uma conta, escrever um número etc. "Nesta escola há um índice muito grande de crianças com distúrbios os mais diversos. Eu acho que o abandono aqui é uma das características marcantes". Esta afirmação é de Janice, que a exemplificou falando de Bruna: "Ela está há três anos nesta escola e ainda não reconhece as letras, não presta atenção em sala. Eu acho que ela tem um problema cognitivo e, além disso, não enxerga bem" (Notas de campo).

Janice atribui as dificuldades que identifica em Bruna aos problemas familiares. Disse que se trata de uma família muito pobre, na qual há violência: "a mãe de Bruna me contou que o pai batia na barriga dela durante a gravidez". Por outro lado, o que deixa Janice convencida de que as dificuldades de Bruna para atender às demandas escolares estão ligadas a problemas familiares é a comparação com outras crianças: "Bruna e Fábio entraram juntos na escola. Fábio é um dos melhores alunos, ele já está alfabetizado. A família dele tem uma estrutura mínima, o pai mora com a mãe, eles se preocupam com o filho".

A referida professora pensa que se Bruna tivesse acesso a profissionais de saúde - tais como oftalmologista, neurologista ou psicólogo -, e apoio psicopedagógico, seu desempenho melhoraria. Bruna poderia ser uma das crianças que chegam à Unidade de Saúde da Família, no consultório da médica Olga, porque não aprendem na escola. Segundo essa profissional:

Quando a criança vai para a escola e não consegue aprender, ou não consegue lidar com os coleguinhas ou écriança agressiva. Eaía professora éque pede: 'Leve essa criança no médico para fazer exame de cabeça'. Quando chega aqui você vai ver, você vai encaminhar 
para fazer uma avaliação psicológica (Trecho de entrevista).

A médica relata que cabe a ela encaminhar a criança para uma avaliação psicológica e, depois, dependendo do resultado, a criança pode ser encaminhada para fazer tratamento com um psicólogo, psiquiatra, neurologista ou algum outro profissional. No entanto, após fazer os encaminhamentos Olga não sabe mais o que acontece com as crianças, pois estas só voltam para ela quando têm alguma queixa de saúde: "Não mental, de outro problema físico".

O principal critério de Janice para avaliar o desempenho de Bruna é o estágio em que se encontra no processo de alfabetização. A preocupação com a alfabetização é um ponto a que convergem cuidadores de várias categorias em Prainha. Entretanto, o lugar da alfabetização e, de um modo mais amplo, dos estudos no projeto de pessoa, envolve importantes distinções entre cuidadores e, como se mostra a seguir, isso permite que Bruna seja tratada de uma forma diferente entre parentes e vizinhos.

\section{Família, parentes e o bairro}

A escola e os valores que ela representa - especialmente a possibilidade de ascensão social -, têm uma presença crescente. Existem várias escolas do Governo, dentre as quais apenas a São Lucas oferece Educação Infantil, para crianças entre quatro e seis anos. Isso não impede que muitas frequentem a pré-escola desde os três anos, pois existem numerosas "escolinhas". Pagar uma pré-escola para os filhos pequenos e continuar fazendo-o nas primeiras séries é o desejo de muitos adultos. Isso está relacionado a diferenças importantes dentro do bairro, entre crianças que "têm condição" de estar em uma escola particular e crianças "carentes", que só podem frequentar a escola do Governo. Em contrapartida, existe outro recurso para ajudar os filhos a terem um bom rendimento: o reforço escolar. Assim, em Prainha é comum encontrar mulheres que oferecem "banca" - o nome usado para o reforço escolar -, e crianças que a frequentam.

Carla, a mãe de Bruna, está ciente das queixas que existem sobre a filha na escola. Nesse sentido, relatou que deseja levar as filhas, Bruna e Clarissa, a um

512 Centro de Atendimento Psicopedagógico. Ainda que ela não procurasse o atendimento que foi sugerido pelos professores da escola, o cuidado não deixava de acontecer, envolvendo uma clara preocupação com a materialidade do corpo de Bruna e dos objetos que a rodeavam no cotidiano.

Os aspectos materiais eram centrais no cuidado de Carla com as filhas. Frequentemente a encontrava penteando-as. Em uma ocasião, comentou: "Todo dia de manhã penteio as quatro meninas, para ninguém dizer que sou uma mãe desligada". "Dar o exemplo" era considerado central para que elas aprendessem a ser "direitas". Demandar a realização de trabalho doméstico também era visto como uma prática importante para a formação das filhas, e o critério era que cada uma assumisse alguma tarefa de acordo com sua idade.

Bruna frequentava a Igreja localizada em frente à casa dela. Quando ia com a mãe à I greja, ficava acompanhando o culto ou então era chamada a sair ao quintal, para participar de brincadeiras organizadas por alguns membros da Igreja. Além de acompanhar a mãe em cultos durante a semana, Bruna participava do "Clubinho da Criança", que acontecia aos sábados de manhã. Observou-se em um desses cultos em que Bruna "louvou". Ela fazia parte de um grupo de nove crianças de várias idades que se apresentou na Igreja: as meninas com o cabelo preso e penteado, saia e blusa de mangas compridas, alguns meninos usando calça comprida e cabelo curto. Todos conheciam bem a letra da música e os adultos acompanhavam. Quando a apresentação terminou, foram aplaudidos e saíram sorrindo.

A capacidade de Bruna de construir relações era identificada e valorizada. Um dia alguém chamou de dentro de uma casa perto da escola São Lucas: "Vocêé a tia de Bruna, não é?". Era Fábio, o colega de turma de Bruna, o menino que, segundo Janice, tem uma família "estruturada" e já está alfabetizado. Ser vista como "tia de Bruna", por Fábio e outras crianças, parece indicar várias situações. Torna a pesquisadora uma pessoa conhecida, mostra a importância do uso de termos de parentesco na construção de vínculos em Prainha e dá certo prestígio a Bruna por ter uma tia que não é do bairro, aparentemente de boa condição socioeconômica. Mas isso também mostra que Bruna é importante, pois é por meio da relação com ela que a pesquisadora deixa de ser uma estranha e se torna alguém que tem 
laços com o bairro. Essa capacidade de Bruna de construir relações, e de mostrar para os colegas que ela tem esses vínculos, não é incluída no olhar da escola sobre ela.

Ser "tia de Bruna" não é um fato trivial: envolve uma relação que é fonte de retribuições afetivas importantes e, também, de reconhecimento. O seguinte episódio é ilustrativo. Um dia em frente à casa de Carla. Bruna, Mariana e uma das irmãs de Carla estavam lá e, em um determinado momento, as meninas fizeram algo que não agradou à tia, que gritou com elas. Carla a apoiou: "pode batermesmo". Ela comentou que deixava a tia bater nas meninas por ser parente, mas se fosse qualquer um não deixaria. Comentou assim: "Se ela é parente, ela pode bater, só não pode matar". Pouco depois Bruna ficou me abraçando e sua tia falou assim: "Ah, eu estou com saudade. Eu não vou ganhar abraço?". Bruna não se mexeu e a tia falou: "Olha que ela vai embora, mas eu fico". Mesmo assim Bruna não se mexeu e a tia disse: "Ah, esse abraço que ela está te dando, esse abraço que está me apertando muito" (Notas de campo).

A tia parecia dizer que não valia a pena para Bruna investir na pesquisadora, que iria embora, enquanto ela (a tia) permaneceria. A tia merecia, então, as atenções de Bruna. Aqui novamente fica claro como Bruna, e o abraço que ela pode oferecer, é importante para sua tia. E, por outro lado, um abraço faz parte de uma relação na qual também pode haver castigo físico. Ambas as expressões corporais - abraço e castigo físico -, são importantes para o cuidado de Bruna e são legítimos, especialmente dentro de uma relação de parentesco consanguíneo.

Por razões de espaço, não é possível aprofundar neste artigo a reflexão sobre parentesco. Entretanto, é importante destacar que, no contexto pesquisado, adultos e crianças têm possibilidades de construir diversos vínculos familiares com base nas linguagens de "sangue" e "consideração". Esses vínculos oferecem afeto e autoridade, nem sempre estão centrados na figura materna ou paterna e, frequentemente, se estendem a uma rede ampla de parentes (Bustamante \& McCallum, 2011).

"Educar" uma criança, dominando sua"natureza", é uma preocupação mais arraigada que a de "dar estudo", e orienta as práticas cotidianas dos parentes. Assim, o castigo físico também faz parte do cotidiano de Bruna. Carla diz que não gosta de bater nas filhas, que o faz quando é necessário - por exemplo, quando Bruna é excessivamente demandante durante as visitas (não obedecendo à norma de "não interferir em conversas de adultos"), quando não cumpre com uma responsabilidade dentro da casa, quando briga com as irmãs ou quando, simplesmente, "bagunça" a casa. Pela experiência corporal, Carla e outros parentes moldam o comportamento de Bruna e das irmãs, e isso é considerado necessário para a educação.

\section{Discussão e Considerações Finais}

O cotidiano de Bruna ilustra dificuldades na relação entre família, escola e serviços de saúde, que podem ser associadas com o fracasso escolar. No entanto, considera-se que o desempenho escolar precisa ser pensado dentro do contexto mais amplo de relações, não só para entender melhor as dificuldades da família - que não consegue acompanhar os aspectos pedagógicos -, mas também oferecer outras possibilidades de cuidado e construção da pessoa para Bruna.

Na escola, o cuidado está relacionado à aplicação de conhecimentos e rotinas planejadas e, diante do insucesso, tende-se a responsabilizar as crianças e suas famílias. São descritas várias situações que favorecem os profissionais a pensarem em aspectos dos seus alunos ou pacientes como se fossem a totalidade da pessoa. Os profissionais atribuem falta de interesse, "desestrutura" ou "distúrbios" às crianças e famílias que não se ajustam às demandas institucionais, sem incluir a si mesmos como parte do contexto que contribui para que a situação da criança seja como é.

As famílias - e os vínculos possibilitados pelo uso de linguagens de parentesco -, oferecem a Bruna amplas possibilidades de relações com adultos, não só mãe e pai, mas tios, vizinhos e frequentadores da Igreja. Assim, entre parentes o cuidado se organiza a partir de preocupações e valores que são centrais no cotidiano, em especial possibilitar que as crianças vivam e construam ativamente o cotidiano familiar. Nesse sentido, foram descritas práticas de cuidado nas quais está presente o objetivo implícito de que a criança seja capaz de lidar com as situações que se apresentam e que, no futuro, se torne um adulto capaz de viver de acordo com seu status. As diferentes práticas de cuidado fazem parte da construção social da pessoa, um processo que não tem um final previsto. 
Tais observações sobre a pessoa em Prainha são parecidas com os achados de outros estudos etnográficos conduzidos em outras áreas do Brasil. Na sua pesquisa sobre os múltiplos aspectos envolvidos na mortalidade infantil em uma área da Zona da Mata, em Pernambuco, Scheper-Hughes (1992) argumenta que as mães dizem que é a criança quem decide viver ou morrer e que, em alguns casos, isso é uma justificativa para deixá-la morrer ("giving up"). Neste argumento está implícito que a criança é vista como um indivíduo singular, que pode ter uma natureza forte, em cujo caso viveria. Por outro lado, como parte de um estudo em um bairro popular do Rio de Janeiro, Goldstein (2003) argumenta que o costume de sua principal informante de resgatar crianças - tratava-se de uma mulher que chegou a ter onze crianças em casa -, constitui uma forma extrema e paradoxal de "holding on", segurar uma criança. A aplicação de rigorosas normas e, às vezes, intensos castigos físicos, fazia parte desse processo, que era visto pela informante como necessário para "educar" os filhos.

Assim, há algo em comum entre o que as autoras citadas descrevem e que se relaciona com o argumento deste estudo: nos dois casos existe grande ênfase na resposta da criança. Para morrer ou viver, na pesquisa de Scheper-Hughes (1992), e para ficar vivendo em casa de um adulto cuidador - ou, ainda, para tornar-se um bandido ou um trabalhador -, na pesquisa de Goldstein (2003). Assim como entre os parentes em Prainha, nas referidas pesquisas os cuidadores oferecem as condições para que a criança expresse sua natureza e consiga viver, adequar-se às regras da nova casa ou optar por uma vida de trabalhador.

Os achados deste estudo são convergentes com aqueles encontrados por Bastos (2000), em cuja pesquisa as justificativas centradas em metas pedagógicas foram a categoria mais frequente apontada pelos pais para explicar a forma com que lidam cotidianamente com os filhos. Desta forma, "o trabalho realizado no âmbito da casa torna-se a principal estratégia pedagógica utilizada pelos pais na educação de seus filhos, sendo esta estratégia vista pelos pais como particularmente apropriada às classes mais pobres" (Bastos, 2000, p.263).

Argumenta-se que as diferenças no cuidado

514 oferecido às crianças estão ligadas a diferentes projetos de pessoa. A escola e os serviços de saúde focam na necessidade de que a criança aprenda. Na família também é importante a aprendizagem de conteúdos acadêmicos, mas o central é que a criança possa, ao mesmo tempo, aceitar e contestar o seu lugar na sociedade. Práticas como o castigo físico, a realização de tarefas domésticas ou a participação em cultos religiosos apontam para o fortalecimento dessa construção, que se dá tanto pensando na criança como futuro adulto quanto na criança como membro ativo da vida social.

No presente estudo foi apontada a permanente agentização do contexto, identificando a inter-relação dos diferentes sistemas nos processos de desenvolvimento e chamando a atenção sobre como esses sistemas contribuem para a construção social da pessoa. Mostrou-se que falhas na escola e nos serviços de saúde, em parte, são atenuadas pelos espaços nos quais funciona a lógica do parentesco. Ao destacar os recursos das crianças e seus parentes para construir um cuidado que envolve projetos totais de pessoa, fora da escola ou da relação com serviços de saúde, não pretende ignorar a importância desses serviços, mas destacar a maneira como as pessoas vivem o dia a dia, construindo significados que possam dar sentido a suas duras condições de vida.

A partir da discussão realizada é possível apontar algumas implicações para pensar as práticas. Oliveira, Bisinoto e Marinho-Araújo (2010) apontam a necessidade de transformar a relação entre família e escola por meio da valorização dos aspectos positivos relacionados ao processo educativo. Nesse sentido, considera-se que conhecer e valorizar o que outros espaços oferecem para crianças que frequentam a escola pode contribuir para melhorar a relação entre escola, família e serviços de saúde. A família também oferece um espaço de socialização e construção social da pessoa, onde a criança recebe estímulos e é valorizada no contato com adultos e outras crianças. Olhar para o parentesco de forma ampla possibilitou essa constatação. Assim, avançamos em relação à perspectiva de Bastos (2000) sobre os modos de partilhar ao apontar a importância de ambientes e pessoas que estão além do contexto familiar restrito e que não se limitam a atividades com objetivos pedagógicos.

Entender como se dá o cuidado, sem avaliá-lo como bom ou ruim, constitui um caminho teórico e 
prático importante. É preciso entender como vivem as pessoas e como são geradas as possibilidades dentro de seus contextos, para poder pensar em serviços que contemplem suas necessidades. Nesse sentido, um tema sobre o qual é necessário refletir mais é o castigo físico que, em muitos casos, é visto como uma atitude necessária para educar a criança e como uma prerrogativa e dever dos parentes mais próximos. Isso se contrapõe à opinião pública que condena o castigo físico, assim como há uma lei que o proíbe. Contudo, este é um tema a ser ampliado em futuras pesquisas.

Como é característico dos estudos qualitativos, aqui não é possível generalizar os achados desta pesquisa. É preciso desenvolver novos estudos. Todavia, espera-se contribuir para o fortalecimento de uma produção científica que, ao compreender as diversas racionalidades que operam no cuidado infantil, contribua para a construção de práticas institucionais mais empáticas com a perspectiva dos usuários.

\section{Referências}

Ayres, J. R. C. M. (2001). Sujeito: intersubjetividade e práticas de saúde. Ciência e Saúde Coletiva, 6(1), 63-72.

Ayres, J. R. C. M. (2004a). Cuidado e reconstrução das práticas de saúde. Interface, 8(14), 73-92.

Ayres, J. R. C. M. (2004b). O cuidado: os modos de ser (do) humano e as práticas de saúde. Saúde e Sociedade, 13(13), 16-29.

Bastos, A. C. S. (2000). Modos de partilhar: a criança e o cotidiano da família. Taubaté: Cabral Editora Universitária.

Becker, H. (1994). Métodos de pesquisa em ciências sociais. São Paulo: Hucitec.

Bustamante, V., \& McCallum, C. A. (2010). O cuidado de grávidas e bebês no contexto do Programa de Saúde da Família: um estudo etnográfico. Interface, 14(34), 243-254.

Bustamante, V., \& McCallum, C. A. (2011). Cuidado infantil na relação entre adultos e crianças na periferia de Salvador. Psicologia e Sociedade, 23(3), 506-515.

Bustamante, V., \& Trad, L. A. B. (2007). Cuidando da saúde de crianças pequenas no contexto familiar: um estudo etnográfico com famílias de camadas populares. Ciência e Saúde Coletiva, 12(5), 1175-1184.

Bourdieu, P. (1996). Razões práticas: sobre a teoria da ação. Campinas: Papirus.

Carvalho, A. M., \& Lordelo, E. R. (2002). Infância brasileira e contextos de desenvolvimento: concluindo. In E. R. Lordelo, A. M. A. Carvalho \& S. H. Koler (Orgs.), Infância brasileira e contextos de desenvolvimento (pp.231-258). São Paulo: Casa do Psicólogo.

Carvalho, M. P. (1999). No coração da sala de aula: gênero e trabalho nas séries iniciais. São Paulo: Xamã.

Chechia, V. A., \& Andrade, A. S. (2005). O desempenho escolar dos filhos na percepção de pais de alunos com sucesso e insucesso escolar. Estudos de Psicologia (Natal), 10(3), 431-440.

Goldstein, D. (2003). Laugher out of place: Race, class, violence and sexuality in a Rio Shantytown. Los Angeles: University of California Press.

Jackson, M. (Ed.). (1996). Things as they are: New directions in phenomenological anthopology. Bloomington: Indiana University Press.

Lordelo, E. R. (2002). Contexto e desenvolvimento humano: quadro conceitual. In E. R. Lordelo, A. M. A. Carvalho \& S. H. Koler (Orgs.), Infância brasileira e contextos de desenvolvimento (pp.231-258). São Paulo: Casa do Psicólogo.

Loyola, M. A. (1984). Médicos e curandeiros: conflito social e saúde. São Paulo: Difel.

Minayo, M. C. S. (2007). O desafio do conhecimento: pesquisa qualitativa em saúde (10ª ed.). São Paulo: Hucitec.

Oliveira, C. Bisinoto E., \& Marinho-Araújo, C. (2010). A relação família-escola: intersecções e desafios. Estudos de Psicologia (Campinas), 27(1), 99-108. doi: 10.1590/S0103-16 6X2010000100012.

Oliveira, M. L. S., \& Bastos, A. C. S. (2000). Práticas de atenção à saúde no contexto familiar: um estudo comparativo de casos. Psicologia: Reflexão e Crítica, 13(1), 97-107.

Pina Cabral, J. (2007). A pessoa e o dilema brasileiro: uma perspectiva anticesurista. Novos Estudos Cebrap, 78, 95-111.

Rabelo, M. C. (1999). A experiência de indivíduos com problema mental: entendendo projetos e sua realização. In M. C. Rabelo, P. C. Alves \& I. Souza (Orgs.), Experiência de doença e narrativa (pp.205-227). Rio de Janeiro: Fiocruz.

Silva, M. V. O. (2003). Psicologia, subjetividade e relações raciais no Brasil. In A. M. B. Bock (Org.), Psicologia e o compromisso social (pp.93-108). São Paulo: Cortez.

Schraiber, L. B. (2005). Equidade de gênero e saúde: o cotidiano das práticas no programa de saúde da família. In W. Vilela \& S. Monteiro (Orgs.), Gênero e saúde: programa de saúde da família em questão (pp.39-61). Rio de Janeiro: Abrasco.

Scheper-Hugues, N. (1992). Death without weeping: The violence of everyday life in Brazil. Berkeley: UCP.

Toren, C. (1997). Ethnography: Theoretical background. In J. T. E. Richardson (Ed.), Handbook of qualitative research methods for psychology and the social sciences. London: BPS.

Recebido em: 23/2/2011

Versão final em: 4/5/2012

Aprovado em: 24/5/2012 
